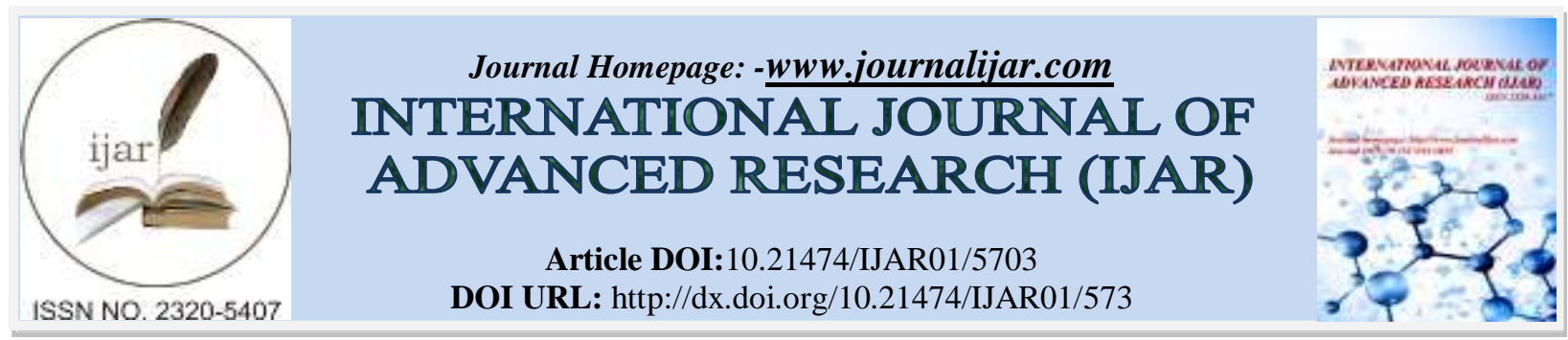

RESEARCH ARTICLE

\title{
A CROSS-SECTIONAL STUDY TO EVALUATE PULMONARY FUNCTION AMONG MEDICAL STUDENTS OF DISTRICT PATIALA.
}

Prof. (Dr.) Amandeep Singh.

Principal, Gian Sagar College of Physiotherapy, Rajpura, Patiala.

\section{Manuscript Info}

Manuscript History

Received: 23 August 2017

Final Accepted: 25 September 2017

Published: October 2017

Key words:-

Spirometry, FVC, FEV1, PEFR.

\section{Abstract}

Background: The medical students, owing to their busy schedule, find less time for their physical fitness. So the present study was conducted to highlight the state of pulmonary function among them.

Aim: The aim of the present study was to evaluate the status of pulmonary function among the medical students with sedentary lifestyle in district Patiala.

Study design: Cross-sectional study design

Sample population: Medical students around Patiala.

Sample size: 100 students

Procedure: Subjects with age 18-25 years and sedentary life style were included in the study. The subjects active in sports, any acute episode of chest infection, any restrictive or obstructive chest disease and any major surgery in the recent past were excluded from the study. Readings were noted down of FVC, FEV1 and PEFR using spirometer. Results: The mean age and BMI of subjects was 22.29 \pm 2.05 $22.58 \pm 4.85$ respectively. The estimated value showed $24.6 \%, 24.3 \%$ and $23.3 \%$ reduction in FVC, FEV1 and PEFR respectively than predicted values. The t-value showed significant reduction in all the parameters.

Conclusion: The conclusion of the present study was that there was a significant reduction in the lung functional parameters of the medical students due to sedentary lifestyle.

Copy Right, IJAR, 2017,. All rights reserved.

\section{Introduction:-}

College life is considered a period, during which individuals are for the most part exposed to stress and lack of time, posing a barrier to adoption of healthy practices (Sajwani et al 2009). Medical students, due to their curriculum, are assumed to have greater knowledge about healthy lifestyle as compared to students with non-medical curriculum. Despite this, these students, due to their busy schedule, are not able to make use of their knowledge in terms of maintaining good health and get prone to exhibit early risk for chronic diseases (Sakamaki et al, 2005)

Medical students of today are physicians are tomorrow and a good physician must be physically fit and mentally alert. Sound health and physical fitness are positively associated with good mental health and well being. People who do regular physical exercise report less anxiety and depression and lower level of stress than do sedentary people (Pratt,2000). 
There have been many studies conducted on the students to assess the practice of nutrition, physical exercise and habits like sleep, smoking and alcohol consumption. Motoko et al., 2007 did a study on skipping meals amongst dental students in Japan and concluded that almost half of the students missed one of the three meals each day. In another study done by Carter et al., 2003 on medical students in UAE, a large percentage of medical students were found to be either underweight or overweight, with insufficient physical activity, unhealthy diet and high level of stress. Irazusta et al., 2006 also highlighted the inclusion of regular physical exercise and nutrition among the nursing students.

Physical fitness is required not only by athletes for better performance but also by non-athletes for maintenance of physical and mental health. It has been concluded that pulmonary function is the long term predictor for overall survival rates, in both the genders and could also be used as a tool in general health assessment (Holger et al, 2000; Parkash et al, 2007).

Pulmonary function test have been increasingly used for assessment of respiratory system regarding airway obstruction, functional degradation as well as response to drugs (Bandyopadhyay et al., 2007). This test is mainly dependent on the level of air pollution, diet, physical activity and anthropometric profile (Marek et al., 2010). Spirometry is an important tool for evaluating cardiovascular and respiratory functions (Azad et al., 2011). Forced vital capacity (FVC) and forced expiratory volume in one second (FEV1) have been considered as strong indicators of respiratory function. Whereas FVC predicts the compliance of lungs and chest wall (Miller et al., 2005), FEV1 detects pulmonary changes easily and effectively (Thaman et al., 2010).

The present study was conducted to evaluate the pulmonary function of medical students in district Patiala of Punjab state of India.

\section{Aim of the study:-}

The aim of the present study was to evaluate the pulmonary function, as evaluated by FEV1, FVC and peak expiratory flow rate (PEFR), among the medical students with sedentary lifestyle.

\section{Need of the study:-}

Since medical students are physicians of tomorrow, they will be subjected to enormous stress, both physically as well as emotionally. The lung function of these students needs to be assessed, so that the appropriate intervention could be made so as to improve their lung function and ultimately their capacity to do work.

\section{Materials andMethods:-}

\section{Study design:-}

Cross-sectional study design

\section{Source of subjects:-}

Medical students from different institutes imparting medical education in district Patiala

\section{Sample:-}

The study was approved by Institutional ethical committee, Gian Sagar group of Institutes. The subjects for this study were constituted by students pursuing both graduation as well as post-graduation in different medical streams of MBBS, BDS, Physiotherapy and Nursing.

100 students in the age range of 18-25 years and who were not engaged in any physical sports were made part of the study. Subjects with any acute episode of chest infection, any restrictive or obstructive chest disease and any history of surgery in recent past of 6 months were excluded from the study.

\section{Procedure:-}

After taking written consent from the subjects, they were given clear instruction about the methodology. The subjects were asked to blow into the computerized spirometer and data was collected by the author. The subject was asked to perform the test for three times and the best reading was noted down. Subjects were instructed to perform the maneuver before being attached to the instrument. To achieve good results before the test, the subjects were familiarized with the machine and the detail instructions and demonstration up to the satisfaction were done. The subjects were asked to loosen tight clothing and were seated comfortably erect with feet firmly on the floor. A nose 
clip was applied to the subject's nose. Then the subject was asked to breathe in fully. The lips were sealed around the disposable mouth piece, and then the subject was asked to blast air out as fast as it can be until the lungs are completely empty. The subject is then asked to breathe in air again as forcibly and fully as possible. Inspiration should be full and unhurried and expiration once begins should be continued without a pause.

\section{Outcome measures:-}

Forced expiratory volume in 1 second (FEV1)

Forced vital Capacity (FVC)

Peak Expiratory Flow Rate (PEFR)

\section{Results and Discussion:-}

The data was analyzed using SPSS 16.0 software and Microsoft excel software of windows 7 ultimate. The data was presented as mean $\pm \mathrm{SD}$ and percentage reduction of capacity. T-test was calculated to estimate whether the reduction in capacity was statistically significant at $95 \%$ level of significance.

Table 1:-Demographic Profile of Subjects

\begin{tabular}{|l|l|}
\hline Parameter & Mean \pm SD \\
\hline Age & $22.29 \pm 2.05$ \\
\hline BMI & $22.58 \pm 4.85$ \\
\hline
\end{tabular}

Table 1 shows the demographic profile of the subjects. The mean BMI of the subjects in the present study indicates that the subjects recruited in the study were in the normal range of BMI.

Table 2:-Difference in the Estimated and Predicted Value of FVC, FEV1 and PEFR

\begin{tabular}{|l|l|l|l|l|}
\hline Parameter & Predicted Value & Estimated value & Difference & \% Reduction \\
\hline FVC & $4.19 \pm 0.77$ & $3.13 \pm 0.72$ & $1.03 \pm 1.17$ & $24.6 \%$ \\
\hline FEV1 & $3.67 \pm 0.66$ & $2.79 \pm 0.57$ & $0.89 \pm 0.99$ & $24.3 \%$ \\
\hline PEFR & $8.25 \pm 1.49$ & $6.33 \pm 1.73$ & $1.92 \pm 2.67$ & $23.3 \%$ \\
\hline
\end{tabular}

Table 3:-Paired t-test Value for Difference in the Predicted and Estimated Value of Different Parameters of Pulmonary Function Test

\begin{tabular}{|l|l|l|}
\hline \multicolumn{1}{|c|}{ Parameter } & \multicolumn{1}{c|}{ t- value } & \multicolumn{1}{c|}{ Significant/ Non-significant } \\
\hline FVC & $4.92 \quad$ Significant \\
\hline FEV1 & 4.8 & Significant \\
\hline PEFR & 3.88 & Significant \\
\hline
\end{tabular}

Table 2 indicates that the estimated values of all the three parameters were less than the predicted value of these parameters. Table 3 shows t-test value to evaluate that whether the difference between the estimated value and predicted value was statistically significant. The calculated value of $t$ of all the three parameters came out to be more than the tabled value indicating that the calculated value of all the three parameters was less than the predicted value.

The results showed that the pulmonary function was reduced to a significant level among the medical students with sedentary lifestyle. It has been found in the numerous previous studies that the students pursuing medical graduation or post-graduation are having less inclination to physical activities owing to their busy curriculum (Motoko et al., 2002; Carter et al., 2003; Sakamaki et al., 2005). Aerobic activity (Angane and Navare, 2016), yoga (Thirupathi and Subramaniam 2016) and physical activity have proven their efficacy on pulmonary function. Therefore, it is recommended that the medical students should include these activities in their busy curriculum to increase their efficiency at both personal and professional level.

\section{Conclusion:-}

The results of the present study showed that the students pursuing various medical degree courses reported a decrease in the pulmonary function. Therefore it is recommended, that they should remain active in physical sports so that they can have good lung functional parameters which are definitely going to assist them in leading a healthy life both personally as well as professionally. It is also recommended that various colleges imparting medical degrees may also include physical education or sports activities so that the stress level of students can be managed. 


\section{Acknowledgement:-}

Heartiest thanks to the management of Gian Sagar Hospital for permitting to conduct the study. The authors would also like to acknowledge all the subjects for being part in this study.

\section{Conflict of Interest:-}

None

Funding:-

None

\section{References:-}

1. Angane, E.Y. and Navare, A.A. (2016): Effects of aerobic exercise on pulmonary function tests in healthy adults. International Journal of Research in Medical Sciences, 4(6): 2059-2063.

2. Azad, A., Gharakhanlou, R., Niknam, A. \&Ghanbari, A. (2011): Effects of Aerobic Exercise on Lung Function in Overweight and Obese Students. Tanaffos, 10(3): 24-31.

3. Bandyopadhyay, A., Tripathy, S., Kamal, R.B., and Basak, A.K. (2007): Peak expiratory flow rate in college students of Bareilly in Uttar Pradesh, India. Indian Biologist, 39(1): 71 - 75.

4. Biswas, A.G. and Khatri, D. (2017): Pulmonary function tests among the students of Sikkim Manipal Institute of Medical Sciences, Gangtok. International Journal of Advanced Research, 5 (9): 336-341.

5. Carter, A.O., Elzubeir, M. Abdulrazzaq, Y.M., Revel, A.D. and Townsend, A. (2003): Health and lifestyle needs assessment of medical students in the United Arab Emirates. Medical Teacher, 25: 492-496.

6. Irazusta, A., Gil, S., Ruiz, F., Gondra, J., Jauregi, A., Irazusta, J. and Gil, J. (2006): Exercise, physical fitness and dietary habits of first year female nursing students. Biological Research for Nursing, 7 (3): 175-186.

7. Khashaba, A.S. (2015): Effect of levels of physical activity on pulmonary function of male saudi university students. International Journal of Sports Science, 5(5): 209-212.

8. Marek, W., Marek, E.M., Muckenhoff, K., Smith, J.H., Degens, P., Kalhoff, H. (2010): Lung function in young adults: which references should be taken? Al Ameen Journal of Medical Sciences, 3 (4): 272 - 283.

9. Miller, M.R., Hankinson, J., Brusasco, V., Burgos, F., Casaburi, R. and Coates, A. (2005): Standardization of spirometry. European Respiratory Journal, 26: 319-338.

10. Motoko, A., Kayoko, S., Keiko, E., Keiko, K., Naomi, Y., Yoko, K. (2002): The relationship among eating habits, lifestyles, and oral health status of students. KokubyoGakkaiZasshi, 69(4): 290-295.

11. Prasad, S., Kumari, S. and Singh, J. (2017): Cross-sectional study on pulmonary function tests among adolescent medical students of VIMS, pawapuri. International Archives of Integrated Medicine, 4(8): 68-71.

12. Sajwani, R.A., Shoukat, S., Raza, R., Sheikh, M.M., Rashid, Q., Siddique, M.S., Panju, S., Raza, H., Chaudhry, S. and Kadir, M. (2009): Knowledge and practice of healthy lifestyle and dietary habits in medical and nonmedical students of Karachi, Pakistan. Journal of Pakistan Medical Association, 59(9): 650-655.

13. Sakamaki, R., Toyama, K., Amamoto, R., Liu, C.J., and Shinfuku, N. (2005): Nutritional knowledge, food habits and health attitude of Chinese university students- a cross-sectional study. Journal of Nutrition, 2005; 4:4.

14. Thaman, R.G., Arora, A. \&Bachhel, R. (2010): Effect of physical training on pulmonary function tests in border security force trainees of India. Journal of Life Sciences, 2: 11-15.

15. Thirupati, C. and Subramaniam, A.K. (2016) Effect of yoga exercise on pulmonary function in young medical students. International Journal of Medical Research \& Health Sciences, 5(11): 341-343. 